\title{
Conhecimento da comunidade odontológica sobre avulsão dental
}

\section{Dental community's knowledge regarding teeth avulsion}

\section{Lilian Cristina Aderne dos Santos', Brenda Cabral Sarmento Teixeira' ${ }^{2}$, Raiane Adorno Trindade ${ }^{3}$ Nathalia Brandão Messias de Figueiredo ${ }^{4}$, Erica Dos Santos Carvalho ${ }^{5}$}

'Autora para correspondência. Universidade Federal da Bahia. Salvador, Bahia, Brasil. lilianaderne@gmail.com 2Universidade Federal da Bahia. Salvador, Bahia, Brasil. brendateixeira_@hotmail.com 3Universidade Federal da Bahia. Salvador, Bahia, Brasil. raianetrindade@hotmail.com ${ }^{4}$ Universidade Federal da Bahia. Salvador, Bahia, Brasil. nathaliabrandaomdef@hotmail.com ${ }^{5}$ Professora Adjunta de Endodontia da FOUBA. Salvador, Bahia, Brasil. erica_carvalho@msn.com

\begin{abstract}
Resumo I A avulsão é uma sequela de traumatismo grave, caracterizada pela total desarticulação do dente com seu alvéolo. O tratamento após a avulsão de um dente permanente deve ser $\circ$ reimplante imediato, caso não seja possível, deve ser mantido em um meio que permita a viabilidade das células do ligamento periodontal. Este trabalho foi realizado com o objetivo de avaliar o conhecimento dos dentistas clínicos e acadêmicos do último ano de Odontologia sobre os meios de armazenamento e reimplante dentário. $O$ estudo é descritivo, com amostra de conveniência de clínicos e formandos $(n=100)$, que responderam questionários sobre a avulsão dentária e o meio utilizado para transportar tais dentes. Com relação à realização do reimplante, $94 \%$ responderam que fariam e $6 \%$ não teriam capacidade de fazer. Dentre os que fariam, $91 \%$ lavariam antes de reposicionar o dente no alvéolo, sendo que $53 \%$ com soro fisiológico, $42 \%$ com água corrente, $3 \%$ com leite e $2 \%$ com água destilada. A maioria encaminharia para um endodontista $(72 \%)$, entretanto, $19 \%$ não encaminharia para um especialista. Quanto ao meio de armazenamento antes do reimplante, $57 \%$ julgaram ser na própria boca, 19\% num frasco com leite, $18 \%$ num frasco com soro e $6 \%$ num frasco com saliva. Sobre o período ideal para o reimplante, $83 \%$ julgaram ser imediatamente após a avulsão, $15 \%$ entre 30 minutos e 1 hora e $2 \%$ entre 1 a 4 horas. O conhecimento sobre o manejo dos dentes avulsionados na comunidade odontológica é satisfatório, entretanto, ainda se percebe alguns equívocos com relação ao tema.
\end{abstract}

Palavras-chave: Avulsão dentária; Reimplante dentário; Odontologia comunitária.

\begin{abstract}
Avulsion is a severe sequel of trauma characterized by total disarticulation of the tooth with its alveolus. Treatment after avulsion of a permanent tooth should be immediate replantation, if this is not possible, it should be maintained in an environment that allows the cell viability of the periodontal ligament. The objective was to evaluate the knowledge of the clinical dentists and academic of the last year of Dentistry on the means of storage and dental replantation. This is a descriptive study, with a convenience sample of clinicians and trainees ( $n=100$ ), who answered questionnaires about dental avulsion and the environment used to transport these teeth. Regarding the replantation, $94 \%$ answered that they could and $6 \%$ would not be able to do the procedure. Of these, $91 \%$ would wash before repositioning the tooth in the alveolus; $53 \%$ with physiological serum, $42 \%$ with running water, $3 \%$ with milk and $2 \%$ with distilled water. Most would recommend the patient to an endodontist $(72 \%)$, however, $19 \%$ would not recommend the patient to a specialist. As for the storage environment before dental replantation, $57 \%$ of the sample judged that the best place would be in the mouth, $19 \%$ in a recipient with milk, $18 \%$ in a physiological serum and $6 \%$ in a recipient with saliva. About the ideal replantation period, $83 \%$ of the sample answer that immediately after the avulsion would be the ideal replantation period, $15 \%$ between 30 minutes and 1 hour after procedure and 2\% between 1 and 4 hours after procedure. Knowledge about the management of avulsed teeth in the dental community is satisfactory, however, some misconceptions about the subject are still noted.
\end{abstract}

Keywords: Dental avulsion; Dental replantation; Community dentistry. 


\section{Introdução}

O traumatismo dentário representa um dos mais sérios problemas de saúde pública entre crianças e adolescentes devido à sua alta prevalência reportada em estudos epidemiológicos, ao seu alto impacto psicossocial e à possibilidade de se estabelecer programas de prevenção e controle, já que possuem causas conhecidas'. Dentre os tipos de trauma, a avulsão dentária ou desarticulação se constitui o de maior gravidade e é caracterizada pelo total deslocamento do dente para fora do seu alvéolo, causando danos estruturais ao ligamento periodontal, cemento, osso alveolar, bem como à gengiva e aos tecidos da polpa ${ }^{2}$.

O reimplante do dente em seu alvéolo sempre deve ser realizado nos casos de dentes permanentes, pois promoverá o restabelecimento da função e da estética, importantes na recuperação psicológica do paciente, além de manter a estrutura óssea alveolar daquela região. Esta preservação do alvéolo é de extrema importância, principalmente no que tange às crianças e adolescentes, ainda em fase de crescimento ósseo, que não podem receber implantes ou próteses fixas definitivas ${ }^{3,4}$.

O sucesso do reimplante e a manutenção do dente por um período mais longo, dependem da viabilidade do ligamento periodontal aderido à superfície radicular, da integridade do cemento e da contaminação bacteriana mínima. Essas condições desejáveis estão diretamente relacionadas com o menor tempo extra-oral, com a manutenção em meio de armazenamento adequado antes do reimplante, com o estágio de formação da raiz e o tempo de chegada ao consultório odontológico ${ }^{5,6}$.

Dentes guardados em meios secos considerados não fisiológicos como lenço, papel ou algodão, promovem o ressecamento e consequente necrose das células do ligamento periodontal, que servirão de estímulo para os diferentes tipos de reabsorção. Já quando o dente é mantido em meio úmido, há maior possibilidade de manutenção da viabilidade do ligamento periodontal remanescente na superfície radicular, elevando as taxas de sucesso do reimplante $^{7,8,5,9}$.

Várias substâncias têm sido propostas e estudadas como meios de conservação de dentes avulsionados, incluindo saliva, soro fisiológico, água, leite, própolis, solução salina balanceada de Hank (HBSS) e outros meios de cultura celular ${ }^{10,8,11,12}$.

Apesar da facilidade de acesso às informações e aos meios de comunicação, ainda se observa muitos profissionais da área de saúde, incluindo os $\mathrm{Ci}$ rurgiões-Dentistas, sem capacidade plena para a realização de um primeiro atendimento adequado frente às situações de traumatismos ${ }^{13,14}$. Nos casos de avulsão, nos quais o atendimento de urgência é fundamental para a manutenção do dente, um protocolo correto deve ser usado, uma vez que, a efetividade da informação sobre o manejo da avulsão dentária, melhora o prognóstico do reimplante ${ }^{15}$.

O presente estudo tem como objetivo avaliar o conhecimento dos dentistas clínicos e acadêmicos do último ano de Odontologia sobre os meios de armazenamento dos dentes avulsionados e a importância do procedimento do reimplante dentário no prognóstico das avulsões.

\section{Metodologia}

A amostra de conveniência foi constituída por $\mathrm{Ci}$ rurgiões-Dentistas que trabalhavam no serviço de urgência de uma Faculdade de Odontologia e estudantes do último período da mesma Faculdade.

No período de Maio/Junho de 2015 aplicou-se um questionário modificado a partir de um estudo prévio realizado por Frujeri \& Costa, $2009^{14}$. Neles continham informações acerca de: noções sobre avulsão e reimplante, realização deste procedimento, meios de armazenamento, manuseio extra-alveolar do dente avulsionado, especialidade indicada para o tratamento da avulsão e tempo para realização do reimplante.

Os dois grupos selecionados foram escolhidos devido ao fato de serem estudantes que já estavam próximos de adentrar no mercado de trabalho e a importância de avaliar a conduta de profissionais que já atuavam na área.

Antes de responder aos questionários todos os participantes assinaram um termo de consentimento livre e esclarecido, onde concordavam que os dados 
coletados poderiam ser utilizados para fins de pesquisa científica. Esta pesquisa foi submetida à análise e aprovação pelo Comitê de Ética em Pesquisa, parecer número 390.316; 11939412.5 .0000 .5024 . Os dados foram digitados no Excel para Windows.

\section{Resultados}

Os dados foram coletados de um total de 70 acadêmicos e 30 dentistas funcionários da Faculdade de Odontologia. Observa-se que $100 \%$ dos acadêmicos e dos dentistas concordaram que o tratamento imediato indicado para os casos de avulsão é o reimplante dentário. Sobre a realização do procedimento, 94,28\% dos estudantes fariam esse procedimento e 5,72\% não. Com relação aos dentistas, 93,33\% responderam que sim e $6,67 \%$ não realizariam o reimplante. A distribuição absoluta e percentual das respostas contidas nos questionários aplicados estão explícitas na tabela 1 .

Tabela 1. Conhecimento dos estudantes de Odontologia do último período e dos cirurgiões-dentistas do serviço de urgência sobre avulsão dentária.

\begin{tabular}{|c|c|c|}
\hline Variável & Acadêmico Último Semestre & Cirurgião-Dentista (Urgência) \\
\hline $\begin{array}{l}\text { Você sabia que em casos de avulsão } \\
\text { de dente permanente o tratamento a } \\
\text { ser indicado é o reimplante dental? } \\
\text { - Sim } \\
\text { - Não }\end{array}$ & $\begin{array}{c}70(100 \%) \\
0(0 \%)\end{array}$ & $\begin{array}{c}30(100 \%) \\
0(0 \%)\end{array}$ \\
\hline $\begin{array}{l}\text { Você faria este procedimento? } \\
\text { - Sim } \\
\text { - Não }\end{array}$ & $\begin{array}{c}66(94,28 \%) \\
4(5,72 \%)\end{array}$ & $\begin{array}{c}28(93,33 \%) \\
2(6,67 \%)\end{array}$ \\
\hline $\begin{array}{l}\text { Você lavaria o dente antes de } \\
\text { recoloca-lo? } \\
\text { - Sim } \\
\text { - Não }\end{array}$ & $\begin{array}{c}64(91,42 \%) \\
2(8,58 \%)\end{array}$ & $\begin{array}{c}27(96,42 \%) \\
1(3,58 \%)\end{array}$ \\
\hline $\begin{array}{l}\text { Lavaria com qual substância? } \\
\text { - Água e escova } \\
\text { - Água corrente } \\
\text { - Outra substância: } \\
\text {-Soro fisiológico } \\
\text { - Água destilada } \\
\text { - Leite } \\
\text { - Sol. de Hank }\end{array}$ & $\begin{array}{c}0(0 \%) \\
30(46,87 \%) \\
34(53,13 \%) \\
30(88,24 \%) \\
2(5,88 \%) \\
2(5,88 \%) \\
0(0 \%)\end{array}$ & $\begin{array}{c}0(0 \%) \\
8(29,62 \%) \\
19(70,38 \%) \\
18(94,73 \%) \\
0(\%) \\
0(0 \%) \\
1(5,27 \%)\end{array}$ \\
\hline $\begin{array}{l}\text { Encaminharia para um cirurgião- } \\
\text { dentista especialista? } \\
\text { - Sim } \\
\text { - Endodontista } \\
\text { - Periodontista } \\
\text { - Cirurgião } \\
\text { - Ortodontista } \\
\text { - Odontopediatra } \\
\text { - Implantodontista } \\
\text { - Não }\end{array}$ & $\begin{array}{c}57(81,42 \%) \\
51(89,46 \%) \\
2(3,5 \%) \\
1(1,76 \%) \\
1(1,76 \%) \\
1(1,76 \%) \\
1(1,76 \%) \\
13(18,58 \%)\end{array}$ & $\begin{array}{c}24(90 \%) \\
21(87,5 \%) \\
1(4,16 \%) \\
2(8,34 \%) \\
0(0 \%) \\
0(0 \%) \\
0(0 \%) \\
6(10 \%)\end{array}$ \\
\hline
\end{tabular}


Tabela 1. Conhecimento dos estudantes de Odontologia do último período e dos cirurgiões-dentistas do serviço de urgência sobre avulsão dentária. (continuação)

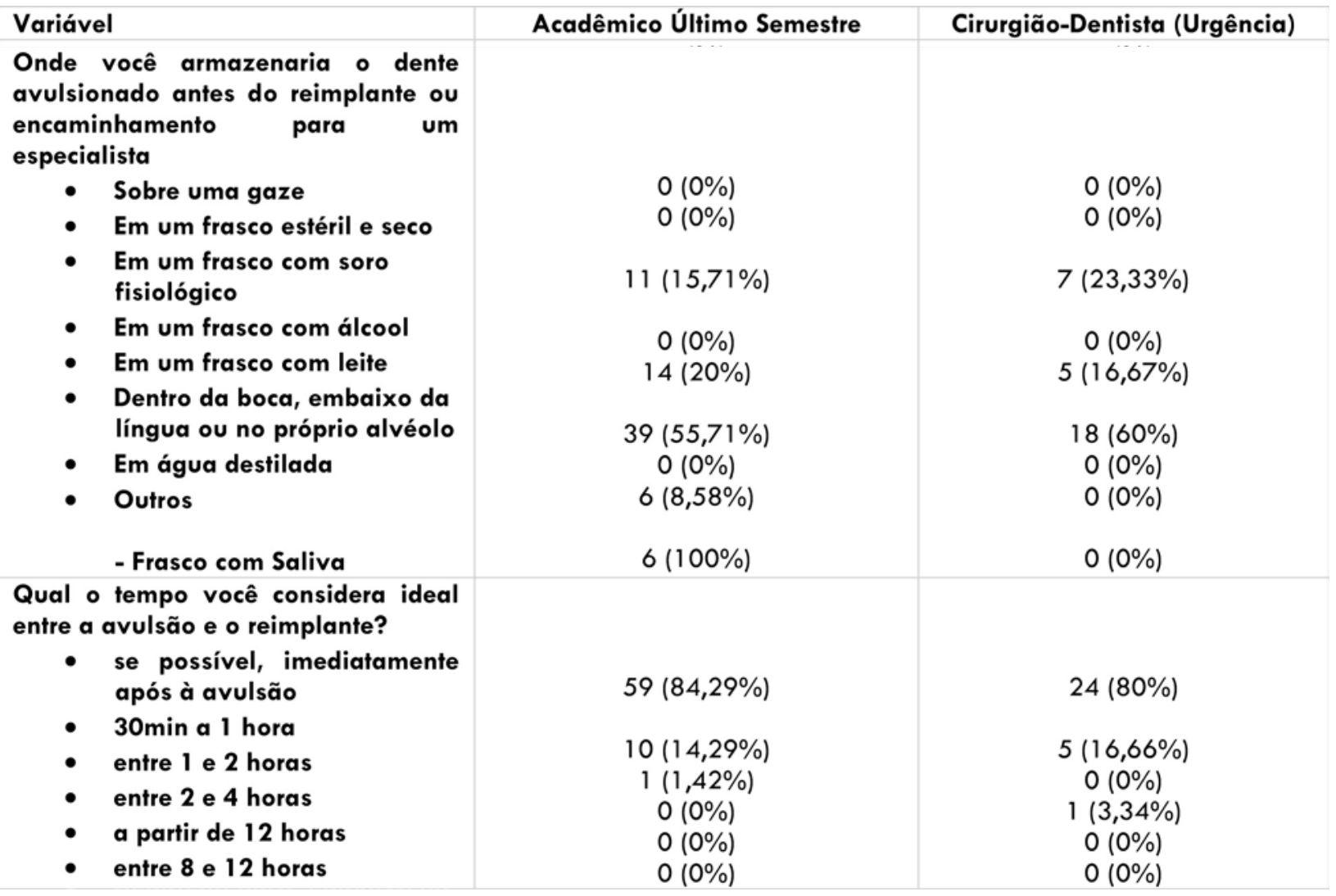

\section{Discussão}

$\mathrm{Na}$ epidemiologia dos traumatismos dentários, a avulsão apresenta uma prevalência que varia de 1 a $16 \%$, sendo os dentes mais acometidos os incisivos centrais superiores, em crianças de 7 a 12 anos de idade, em decorrência das atividades próprias da infância e da adolescência que favorecem aos traumas dentais e são intensificadas pela menor quantidade de fibras do ligamento periodontal do dente recém-erupcionado e com rizogênese incompleta ${ }^{3,16}$.

Nos casos da avulsão de um dente permanente, o reimplante dentário sempre deve ser tentado, evitando assim, o comprometimento da estética e problemas psicossociais que podem ser desenvolvidos pelos indivíduos acometidos. O conhecimento sobre a conduta frente aos casos de avulsão dentária, bem como os meios de armazenamento dos dentes avulsionados deve estar bem consolidado entre os estudantes e profissionais da área da Odontologia. Além disso, os profissionais da área de saúde, professores de escolas primárias, professores de educação física, pais e a população de uma forma geral deveriam ter informações sobre esse tipo de sequela, com o intuito de diminuir os casos de perda dessas unidades dentárias pelo progresso das reabsorções radiculares ${ }^{17,18,19}$.

Na pesquisa em questão, $100 \%$ dos acadêmicos e $100 \%$ dos dentistas responderam que o tratamento indicado em casos de avulsão dentária seria o reimplante. Entretanto, outros estudos avaliaram que muitos dentistas ainda se consideram inaptos para decidir $\circ$ procedimento imediato frente às avulsões dentárias ${ }^{13,20}$. Quanto aos acadêmicos, algumas pesquisas demonstram um nível de conhecimento insatisfatório por parte dos estudantes sobre manobras a serem feitas em casos de avulsão, visto que estes já deveriam demonstrar melhor grau de conhecimento adquirido durante seu processo de formação ${ }^{13,21}$.

Sabe-se que quanto maior for o tempo do dente fora do alvéolo, maior será a chance de necrose das células do ligamento periodontal, aumentando assim, a possibilidade de reabsorção radicular ${ }^{22}$. Com relação à variável tempo extra alveolar, foi possível constatar que a maioria dos entrevistados julgou oportuno reimplantar um dente avulsionado até no máximo 1 hora após o trauma. Vale ressaltar que a partir de 15 minutos fora do alvéolo e em 
ambiente seco, as células do ligamento periodontal aderidas à superfície radicular já começam a se tornar inviáveis, retificando a importância de o reimplante ser imediato ${ }^{23}$.

Caso não seja possível o reimplante imediato no local do acidente, é necessário que se utilize um meio adequado para armazenar o dente avulsionado, mantendo assim, a viabilidade das células do ligamento periodontal. $O$ meio de armazenamento ideal necessita ter capacidade clonogênica, $\mathrm{pH}$ balanceado, nutrientes para as células do ligamento periodontal, mínima contaminação microbiana, osmolaridade fisiológica, ser acessível e manter-se numa temperatura apropriada para favorecer 0 crescimento celular ${ }^{24,5}$. Na atualidade, ainda não existe este meio ideal, entretanto, muitas substâncias vêm sendo estudadas para esta finalidade, dentre elas podemos citar a própolis, a clara de ovo, 0 leite, O HBSS, a água de coco, o extrato de Aloé Vera, meios de cultura, soro fisiológico e extrato de chá verde e $^{7,5,12,9}$.

Em nosso estudo, a maioria dos acadêmicos e dentistas sugeriram a boca, embaixo da língua ou 0 próprio alvéolo como melhores meios para levar os dentes avulsionados até $\circ$ pronto atendimento, - que também é preconizado pela Associação Internacional de Traumatologia Dentária4. Uma boa porcentagem dos entrevistados $(26,19 \%$ dos Acadêmicos e $27,28 \%$ dos cirurgiões-dentistas) relatou que o soro fisiológico era o melhor meio de armazenamento, contudo, embora este possua osmolaridade balanceada e ausência de bactérias, o acompanhamento em humanos mostrou uma redução do reparo periodontal, quando os dentes foram mantidos por mais de 20 minutos em soro fisiológico ${ }^{24}$. Já - leite, fornece umidade e nutrição para preservar os remanescentes periodontais aderidos à superfície radicular, possui um fator de crescimento epidérmico que impede a proximidade com o tecido ósseo, diminuindo a probabilidade de anquilose, além de poder manter a viabilidade celular por até 10 ho$\operatorname{ras}^{10}$.

Alguns cuidados devem ser tomados com a técnica do reimplante, pois procedimentos inadvertidos podem influenciar negativamente no prognóstico do mesmo. Sendo assim, antes do reimplante, deve-se irrigar o alvéolo com soro fisiológico e lavar copiosamente o dente, evitando tocar na raiz para não provocar mais danos à camada de cemento ${ }^{4}$. Esse conhecimento foi constatado aqui e em outras pesquisas anteriores, onde a maioria dos entrevistados afirmou a importância dessa lavagem anterior ${ }^{20,21}$.

Após o reimplante e a contenção flexível, deve-se sempre avaliar a possibilidade de tratamento endodôntico, principalmente no que tange aos dentes permanentes com rizogênese completa. Neste sentido, é sempre importante a avaliação de um endodontista, não só pela possibilidade de necrose pulpar, como também pela grande probabilidade de desenvolvimento de reabsorções radiculares externas $^{13}$. Nesse quesito, a maior parte das respostas de indicações tanto dos acadêmicos $(89,46 \%)$ quanto dos profissionais $(87,5 \%)$ foi para os especialistas em Endodontia, embora também fossem citados outros encaminhamentos.

Santos et al., $2010^{25}$, em um estudo com cirurgiões-dentistas, enfermeiros e professores de educação física constataram um desempenho satisfatório dos cirurgiões-dentistas quanto ao conhecimento do meio de preservação extra-alveolar e ao manuseio dentário durante a limpeza antes do reimplante. No entanto, os profissionais Educadores Físicos apresentaram níveis de conhecimentos semelhantes aos Enfermeiros, estando ambas as classes ainda distantes de um resultado satisfatório, no que diz respeito aos procedimentos básicos emergenciais em um quadro de avulsão.

A avulsão dentária é um tipo de traumatismo grave, pois causa danos ao ligamento periodontal, cemento, osso alveolar, gengiva e os tecidos da polpa. Entretanto, condutas simples e adequadas tomadas no momento do acidente podem reduzir os riscos e elevar as chances de sucesso do reimplante ${ }^{2}$. Sendo assim, campanhas de esclarecimento e alerta sobre os cuidados com os dentes traumatizados merecem destaque não só na comunidade odontológica, como com a população de um modo geral ${ }^{14,19}$.

Diante do exposto, observa-se a necessidade de implantação de programas de educação continuada que reforcem constantemente os protocolos urgenciais e preventivos das lesões dentárias traumáticas, tanto a nível de graduação, quanto de pós graduação, pois o reparo e a manutenção dos dentes traumatizados requerem habilidades clínicas, conhecimento, diagnóstico do problema, adequado 
atendimento urgencial, bem como apropriado tratamento e acompanhamento a longo prazo.

\section{Considerações finais}

O conhecimento sobre a conduta frente a casos de avulsão dentária, bem como os meios de armazenamentos dos dentes avulsionados na comunidade odontológica é satisfatório, entretanto, ainda se percebe alguns equívocos com relação ao tema.

\section{Conflitos de interesses}

Nenhum conflito financeiro, legal ou político envolvendo terceiros (governo, empresas e fundações privadas, etc.) foi declarado para nenhum aspecto do trabalho submetido (incluindo mas não limitandose a subvenções e financiamentos, conselho consultivo, desenho de estudo, preparação de manuscrito, análise estatística, etc).

\section{Referências}

1. Paiva PCP, Paiva HN, Oliveira Filho PM, Côrtes MIS. Prevalence and risk factors associated with traumatic dental injury among 12-year-old schoolchildren in Montes Claros, MG, Brazil. Cien e Saude Colet. 2015; 20(4):1225-1233. doi: $10.1590 / 1413-81232015204.00752014$

2. Moradian H, Badakhsk S, Rahimi M, Hekmatfar S. Replantation of an Avulsed Maxillary Incisor after 12 Hours: Three-Year Follow-Up. Iran Endod J. 2013;8(1):33-36.

3. Andreasen JO, Andreasen FM, Andersson L. Textbook and Color Atlas of Traumatic injuries to teeth. 4th ed. USA: Blackwell Munksgard; 2007.

4. Andersson L, Andreasen JO, Day P, Heithersay G, Trope $M$, Diangelis AJ et al. International Association of Dental Traumatology guidelines for the management of traumatic dental injuries: 2 . Avulsion of permanent teeth. Dent Traumatol. 201 2;28(2):88-96. doi: $10.1111 /$ i.16009657.2012.01125.x

5. Poi WR, Sonoda CK, Martins CM, Melo ME, Pellizzer EP, de Mendonça MR et al. Storage Media For Avulsed Teeth: A Literature Review. Brazilian Dental Journal. 2013;24(5):437445. doi: $\underline{10.1590 / 0103-6440201302297}$

6. Yadar S, Sisodia N, Jha V, Yadav M. Dental exarticulation. Niger J Clin Pract. 2015;18(3):426-428. doi: 10.4103/1119-3077.151804
7. Khademi AA, Saei S, Mohajeri MR, Mirkheshti N, Ghassami $\mathrm{F}$, Torabi nia $\mathrm{N}$ et al. A New Storage Medium for an Avulsed Tooth. J Contemp Dent Pract. 2008;9(6):25-032.

8. Mori GG, Nunes DC, Castilho RL, de Moraes IG, Poi WR. Propolis as storage media for avulsed teeth: microscopic and morphometric analysis in rats. Dent Traumatol. 2010;26(1):80-85. doi: 10.1111/i.16009657.2009.00856.x

9. Bharath MJ, Sahadev CK, Ramachandra PKM, Rudranaik $S$, George J, Thomas A. Comparative evaluation of four transport media for maintaining cell viability in transportation of an avulsed tooth - An in vitro study. J Int Soc Prev Community Dent. 2015;5(1):69-73. doi: 10.4103/2231$\underline{0762.151981}$

10. Pearson RM, Liewehr FR, West LA, Patton WR, McPherson JC 3rd, Runner RR. Human periodontal ligament cell viability in milk and milk substitutes. J Endod. 2003;29(3):184-86. doi: $10.1097 / 00004770-200303000-00005$

11. Ahangari Z, Alborzi S, Yadegari Z, Dehghani F, Ahangari L, Naseri M. The Effect of Propolis As A Biological Storage Media on Periodontal Ligament Cell Survival in An Avulsed Tooth: An In Vitro Study. Cell J. 2013;15(3):244-249.

12. Badakhsh S, Eskandarian T, Esmaeilpour T. The Use of Aloe Vera Extract as a Novel Storage Media for the Avulsed Tooth. Iran J Med Sci. 2014;39(4):327-332.

13. Kostopoulou MN, Duggal MS. A study into dentists'knowledge of the treatment of traumatic injuries to young permanent incisors. Int J Paediatric Dent. 2005; 15(1):10-9. doi: $10.1111 /$ i.1365-263X.2005.00588.x

14. Frujeri MLV, Costa Jr ED. Effect of a single dental health education on the management of permanent avulsed teeth by different groups of professionals. Dent Traumatol. 2009;25(3):262-271. doi: $10.1111 /$ i.16009657.2008.00760.x

15. Petrovic B, Markovic D, Peric T, Blagojevic D. Factors related to treatment and outcomes of avulsed teeth. Dent Traumatol. 2010;26(1):52-59. doi: 10.1111/i.16009657.2009.00836.x

16. Rodrigues TLC, Rodrigues FG, Rocha JF. Avulsão dentária: Proposta de tratamento e revisão da literatura. Rev Odontol Univ Cid São Paulo. 2010;22(2): 147-53.

17. Freitas DA, Freitas VA, Antunes SLNO, Crispim RR. Avaliação do conhecimento de acadêmicos de Educação Física sobre avulsão/reimplante dentário e a importância do uso de protetor bucal durante atividades físicas. Rev. Bras. Cir. Cabeça Pescoço. 2008;37(4):215-218.

18. Curylofo PA, Lorencetti KT, da Silva SRC. Avaliação do conhecimento de professores sobre avulsão dentária. Arq Odontol. 2012;48(3):175-180. 
19. Loo TJ, Gurunathan D, Somasundaram S. Knowledge and attitude of parents with regard to avulsed permanent tooth of their children and their emergency management-Chennai. J Indian Soc Pedod Prev Dent. 201 4;32(2):97-107. doi: $10.4103 / 0970-4388.130781$

20. Raoof M, Vakilian A, Kakoei S, Manochehrifar $H$, Mohammadalizadeh S. Should Medical Students Be Educated About Dental Trauma Emergency Management? A Study of Physicians and Dentists in Kerman Province, Iran. J Dent Educ. $2013 ; 77(4): 494-501$.

21. Fujita Y, Shiono Y, Maki K. Knowledge of emergency management of avulsed tooth among Japanese dental students. BMC Oral Health. 2014;14(34):2-6. doi: 10.1186/1472-6831-14-34

22. Karayilmaz H, Kirzioglu Z, Gungor OE. Aetiology, treatment patterns and long-term outcomes of tooth avulsion in children and adolescents. Pak J Med Sci. 2013;29(2):464468.

23. Carvalho ES, Costa FTS, Campos MS, Anbinder AL, Neves ACC, Habitante SM et al. Root surface treatment using diode laser in delayed tooth replantation: radiographic and histomorphometric analyses in rats. Dent Traumatol. 2012; 28(6):429-36. doi: $10.1111 / i .1600-9657.2011 .01108 . x$

24. Andreasen JO, Borum MK, Jacobsen HL, Andreasen FM. Replantation of 400 avulsed permanent incisors. 1. Diagnosis of healing complications. Endod Dent Traumat. 1995; $11(2): 51-58$

25. Santos MESM, Palmeira PTSS, Soares DM, Souza CMA, Maciel WV. Nível de conhecimentodos estudantes de Enfermagem, Educação Física e Odontologia sobre traumatismo dentoalveolar do tipo avulsão: estudo preliminar. Rev Cir Traumatol Buco-Maxilo-fac. 2009;9(3):105-112. 